\title{
Limitations of conventional models and a conceptual framework for a nutrient flow representation of energy utilization by animals
}

\author{
Stephen Birkett* and Kees de Lange \\ Department of Animal and Poultry Science, University of Guelph, Guelph, Ontario, Canada N1G 2W1 \\ (Received 31 October 2000 - Revised 1 June 2001 - Accepted 5 July 2001)
}

\begin{abstract}
Conventional models of energy utilization by animals, based on partitioning metabolizable energy (ME) intake or net energy (NE), are reviewed. The limitations of these methods are discussed, including various experimental, analytical and conceptual problems. Variation in the marginal efficiency of utilizing energy can be attributed to various factors: diet nutrient composition; animal effects on diet ME content; diet and animal effects on ME for maintenance (MEm); experimental methodology; and important statistical issues. ME partitioning can account for some of the variation due to animal factors, but not that related to nutrient source. In addition to many of the problems associated with ME, problems with NE pertain to: estimation of NE for maintenance (NEm); experimental and analytical methodology; and an inability to reflect variation in the metabolic use of NE. A conceptual framework is described for a new model of energy utilization by animals, based on representing explicit flows of the main nutrients and the important biochemical and biological transformations associated with their utilization. Differences in energetic efficiency from either dietary or animal factors can be predicted with this model.
\end{abstract}

Modelling: Energy utilization: Nutrient flow representation

Mathematical models can integrate theories and observations into a coherent framework that can be useful for both conceptual and computational purposes. Animal models have been developed for a variety of species and applications: pig growth (Whittemore \& Fawcett, 1976; Black et al. 1986; Moughan et al. 1987; Pomar et al. 1991a; Technisch Model Varkensvoeding, 1991); reproducing sows (Pomar et al. 1991b; Pettigrew et al. 1992); poultry production (Zoons et al. 1991; Hruby et al. 1994); growing sheep (Gill et al. 1984); growing fish (Machiels \& Henken, 1986; Cho \& Bureau, 1998); growing and reproducing beef cattle (Buchanan-Smith \& Fox, 2000); and dairy cattle (Baldwin et al. 1987). Some of these models are based exclusively on empirical observations, such as direct relationships between daily lysine and energy intake, and average daily gain and backfat thickness in growing pigs, established using multiple linear regression (Carr et al. 1979). Application of such empirical models is limited to animal, environmental, and management conditions similar to those used in the trials on which they are based. Furthermore, this approach to representing animal production offers little insight into the mechanistic biological principles of which the measured performance is a consequence.

In contrast to the empirical approach, highly complex mechanistic biochemical models have been developed to simulate nutrient metabolism at the level of individual tissues, using differential equations to represent (noncausally) relationships between the various metabolite flow rates. These mechanistic models are most useful for demonstrating biological and biochemical principles, especially at the cellular and inter-cellular levels. Wholeanimal models of this type have been developed, for example in monogastric metabolism (Schulz, 1978), preruminant calves (Gerrits, 1996), and especially in ruminant animals, such as sheep (Gill et al. 1984), or lactating cows (Baldwin et al. 1987; Dijkstra et al. 1992). In practice, mechanistic models are not easy to use effectively to predict whole-animal response. This illustrates the point that when modelling a physical system a high degree of detail should be used mainly at the spatial level (e.g. genetic, cellular, whole-animal, groups of animals) which the model is primarily designed to represent. A direct representation of the biological mechanisms controlling

\footnotetext{
Abbreviations: BE, basal energy requirement; HP, heat production; ME, metabolizable energy; MEm, metabolizable energy for maintenance; NE, net energy; NSN, non-specific nitrogen; RE, retained energy; REL, retained energy in lipid; REP, retained energy in protein; uN, urinary nitrogen.

* Corresponding author: Dr Stephen Birkett, fax +1 519836 9873, email birketts@wright.aps.uoguelph.ca
} 
nutrient metabolism at the tissue level is neither necessary, nor desirable, for modelling and understanding the factors which drive that control at the whole-animal level. Much of the internal metabolic detail in a mechanistic model is essentially noise when viewed at the higher spatial level. Furthermore, the very large number of parameters that must be estimated, in some instances without solid experimental observations, limits predictive flexibility when extrapolating to different conditions and inputs, a weakness shared with the empirical model.

A representation of energy utilization is central to any animal production model. Conventional approaches use phenomenological observations at the whole-animal level to relate energy intake to body maintenance and (or) production functions, either partitioning metabolizable energy (ME) intake (Kielanowski, 1966; Emmans, 1994; National Research Council, 1998), or the supply of net energy (NE) (Noblet et al. 1994a; van Milgen et al. 1998). This present article explores these two conventional methods, examines their limitations, and discusses various experimental, analytical, and conceptual problems with the techniques. An alternative approach for representing energy utilization which avoids many of these problems is presented. A conceptual framework is described to extend and generalize the simple nutrient partitioning models by representing explicitly the material flows of energy-yielding substrates, i.e. energy flow is an implicit consequence of material flow and the corresponding energy density of that material. Phenomenological observations based on wholeanimal response are combined with simple biochemical transformations that model the main metabolic pathways of using dietary nutrients for the various body functions. Differences in energetic efficiency which are a consequence of either the source, or metabolic use, of nutrients are explicitly represented and can be predicted based on the contribution of specific biological and biochemical processes, i.e. heat increments are closely associated with the various biological processes of which they are a consequence. Furthermore, the residual heat output which is not associated with production is considerably smaller than conventional 'maintenance energy', and can be more closely linked to an animal's physical state. As a conceptual model of nutrient utilization, the fundamental structure of this nutritional process model is applicable across species.

\section{Conventional methods of representing energy utilization}

Partitioning metabolizable energy intake

The classical energetic hierarchy (Fig. 1) defines ME as the useable energy supplied to an animal from dietary nutrients, after accounting for faecal, gaseous and urinary losses (Knox, 1979). For a particular species these physical losses are considered to be a fixed characteristic of the diet, independent of intake and metabolic state (e.g. Agricultural Research Council, 1981; National Research Council, 1998). The simplest approach to partitioning ME intake is in terms of its use by an animal for production, for instance as retained energy (RE), and a residual amount (MEm) associated with maintenance:

$$
\mathrm{ME}=\mathrm{MEm}+\left(1 / \mathrm{k}_{\mathrm{g}}\right) \mathrm{RE} .
$$

Different energetic efficiencies are associated with production, for instance for growth $\left(\mathrm{k}_{\mathrm{g}}\right)$, as compared with maintenance purposes. This simple model fails to take into account the significantly different efficiencies (e.g. Thorbek, 1967) that relate to energy retention as lipid $\left(\mathrm{k}_{\mathrm{f}}\right)$ and protein $\left(\mathrm{k}_{\mathrm{p}}\right)$. In order to model energy utilization more accurately for varying lipid:protein ratios in the RE, Kielanowski $(1966,1976)$ subdivided the RE term into RE in lipid (REL) and in protein (REP):

$$
\mathrm{ME}=\mathrm{MEm}+\left(1 / \mathrm{k}_{\mathrm{f}}\right) \mathrm{REL}+\left(1 / \mathrm{k}_{\mathrm{p}}\right) \mathrm{REP} .
$$

The use of multiple linear regression to derive values for $\mathrm{k}_{\mathrm{f}}$, $\mathrm{k}_{\mathrm{p}}$ and MEm makes the assumption that the marginal efficiency of utilizing ME for each product is constant, i.e. independent of level of performance, energy intake, metabolic state, and so on.

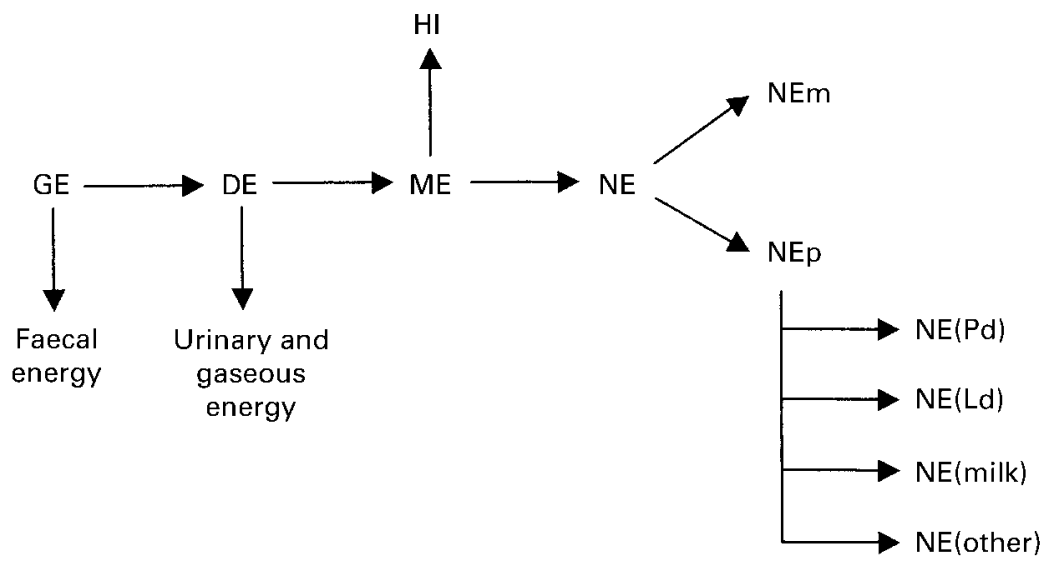

Fig. 1. Classical energy hierarchy. Digestible energy (DE) is gross energy intake (GE) less faecal losses; metabolizable energy (ME) is DE less urinary and gaseous losses; net energy (NE) is ME less heat increment of feeding $(\mathrm{HI})$. NE can be further subdivided into net energy for maintenance (NEm) and products (NEp); NEp can be attributed to retained protein (Pd), retained lipid (Ld), milk, and so on. 
Kielanowski's equation is the basis for representing energy utilization in many animal growth models (e.g. Whittemore \& Fawcett, 1976; Agricultural Research Council, 1981; Black et al. 1986; Moughan et al. 1987; Technisch Model Varkensvoeding, 1991; de Lange, 1995; National Research Council, 1998). Properly parameterized ME models of this type can predict energetic performance reasonably accurately with diets and conditions similar to those for which the observations relating REL and REP to $\mathrm{ME}$ intake were obtained. Reported values for $\mathrm{k}_{\mathrm{f}}$ and $\mathrm{k}_{\mathrm{p}}$ vary widely: 0.70 and 0.58 (Close et al. 1973); 0.8 and 0.6 (Noblet et al. 1991); 0.74 and 0.56 (Agricultural Research Council, 1981); 0.6 and 0.51 (Tess, 1981); 0.74 and 0.45 (Pullar \& Webster, 1977); 0.75 and 0.44 (Whittemore, 1997; National Research Council, 1998). This variation illustrates some of the problems inherent in adequately defining and partitioning ME intake: (1) diet effects on utilization of ME for various body functions; (2) animal effects on diet ME content; (3) diet and animal effects on MEm; (4) experimental methodology used to evaluate the partitioning of ME intake; (5) statistical issues associated with deriving independent estimates of MEm, $\mathrm{k}_{\mathrm{f}}$ and $\mathrm{k}_{\mathrm{p}}$.

Characterizing a diet using a fixed ME (or dietary energy) density, as is done in many experimental analyses and feeding tables (Agricultural Research Council, 1981; Noblet et al. 1987, 1994a; Emmans, 1994; Möhn \& de Lange, 1997; Azevedo et al. 1998; Centraal Veevoeder Bureau, 1998; National Research Council, 1998), always entails a loss of information. Different sources of energy cannot be distinguished and therefore the different efficiencies with which nutrients are utilized as energy substrates cannot be taken into account (Noblet et al. 1993; Black, 1995). This problem is specifically addressed by the concept of net energy.

A fixed dietary ME density is also biologically inconsistent. In particular, the utilization of dietary protein, i.e. partitioning of digested protein between animal products and as an energy substrate, influences diet ME content (Whittemore, 1983, 1997). This problem may be overcome by separating digestible energy intake derived from protein and non-protein sources, and explicitly representing the utilization of dietary protein in the model (Whittemore \& Fawcett, 1976; Moughan et al. 1987; de Lange, 1995). Urinary excretion of energy, which is closely associated with urinary $\mathrm{N}(\mathrm{uN})$ excretion, can be adjusted with this method to reflect variation in the level of protein catabolism. This approach also allows for assigning an energy cost (heat loss) to excretion of uN (Emmans, 1994). Other diet and animal factors contribute to diet ME content, as illustrated by the considerable variation in the relationship between $\mathrm{uN}$ and urinary energy content across species and studies. Hoffmann \& Klein (1980) give the results of regressions on over three thousand observations of urinary energy content for cattle, sheep, pigs and rats. A wide range of values is reported, both between species, from $28.5 \mathrm{~kJ} / \mathrm{g}$ uN (rats) to $62.5 \mathrm{~kJ} / \mathrm{g} \mathrm{uN}$ (cows), and within species, with SE as large as $21 \mathrm{~kJ} / \mathrm{g} \mathrm{uN}$. This variation can be expected, reflecting variation in the composition of both the nitrogenous and non-nitrogenous components of urine. In mammals, for example, urea $(22.5 \mathrm{~kJ} / \mathrm{g} \mathrm{N})$ normally accounts for $80-90 \%$ uN (Hawk, 1965); the non-specific N (NSN) fraction provides a much higher energy content, for example from amino acids (e.g. $140 \mathrm{~kJ} / \mathrm{g} \mathrm{N})$, or creatinine $(56 \mathrm{~kJ} / \mathrm{g} \mathrm{N})$. A decrease in total uN excretion is always accompanied by a decrease in the urea N:NSN ratio in urine (Hawk, 1965), and consequently an increase in the energy content of urine can be expected with a reduction of total $\mathrm{uN}$ excretion. These considerations are important because an accurate estimate of urinary energy content is necessary for calculating simulated $\mathrm{ME}$ intakes in the calibration of the nutritional process model (Birkett \& de Lange, 2001b).

Partitioning of ME intake via multiple linear regression is usually based on the a priori assumption that MEm is an allometric function of body weight, either independently estimated (Close et al. 1973; Bikker, 1994; Noblet et al. $1994 a, 1999)$, or determined as an additional regression variable (Noblet et al. 1989b). However, the former method incorrectly forces a fixed amount of energy from ME intake to be available for growth, and, with either approach, the regression coefficients are very sensitive to the assumed relationship between MEm and body weight or body components (Tess, 1981; Noblet \& Henry, 1991). Even though MEm is about one-third of total heat production (HP) in growing animals, the concept may be biologically and functionally ambiguous (Knap, 2000). For example, for a growing animal, maintenance energy requirement is often defined as the ME intake which results in energy balance, i.e. zero RE. There is, however, convincing evidence for significant catabolism of body lipid and positive protein retention at very low ME intakes in growing pigs (Fuller et al. 1976; Close et al. 1978, 1982; Kyriazakis \& Emmans, 1992; Kyriazakis et al. 1993). Reported levels of protein retention at zero energy balance are also quite variable. Furthermore, maintenance energy requirements are known to vary between groups of animals and are affected by feed, animal, and environmental factors (Bernier et al. 1996; Knap, 2000). Maintenance energy will also vary within a group of animals according to individual behaviour and activity levels (van Milgen et al. 1998).

The choice of method used to determine protein and lipid accretion rates, traditionally either respiration calorimetry or comparative slaughter techniques, has an influence on the determined energetic efficiencies (Webster, 1989). Both methods divide an observed ME intake completely between RE and HP, calorimetry calculating RE from a measured $\mathrm{HP}$, and vice versa for the serial slaughter method. McCracken \& Rao (1989) report a $9 \%$ higher HP for pigs in comparative slaughter conditions as compared with those confined in metabolism crates. Systematic errors in measuring feed intake or calculating $\mathrm{ME}$ intake have opposite effects in the two techniques, an overestimate of $\mathrm{ME}$ intake, for instance, causing an overestimate of energetic efficiency with calorimetry, and an underestimate with comparative slaughter. $\mathrm{N}$ balance techniques, required in conjunction with respiration calorimetry, are believed to overestimate $\mathrm{N}$ retention as compared with serial slaughter (Kielanowski, 1976; Möhn \& de Lange, 1997; Möhn et al. 2000), thereby overestimating $\mathrm{k}_{\mathrm{p}}$. Any error in the calorimetry coefficients directly affects only the REL term, and therefore the calculated $\mathrm{k}_{\mathrm{f}}$ value. Finally, sustained manipulation of the composition of gain in a serial slaughter trial will eventally produce animals with 
significantly different chemical body compositions, influencing the MEm term.

To obtain a meaningful partitioning of ME intake animals should be properly adjusted to both the diet composition and the intake level before measuring HP. An equilibrium HP cannot be expected after a sudden change in feed intake, until visceral organ size, an important contributor to HP, has adapted from the previous intake (Koong et al. 1982; Yen, 1997). The required period of adaptation is likely to be considerable; for example, subsequent to a $50 \%$ feed restriction, McCracken \& McAllister (1984) report a gradual reduction in HP over a period of $20 \mathrm{~d}$. Associating non-equilibrium $\mathrm{HP}$ values with a given $\mathrm{ME}$ intake confounds the diet-related heat increment of feeding with a variable and unpredictable animal-related heat increment, the residual effect of the previous feeding regimen on HP.

To avoid inconsistent values for the regression coefficients it is essential to have observations with a wide range of ME intakes, and, at each intake level, wide variation in the distribution of ME between animal products. In addition, MEm must reasonably be expected to be identical between treatments. These conditions are difficult to achieve in practice, since variation in animal type (genotype, body weight, etc.) is often used to provide the required experimental variation in distribution of energy to different products (Tess, 1981). The restriction of a common MEm between treatments can be partially circumvented by dividing these into subgroups that individually satisfy the requirement. For example, Pullar \& Webster (1977) used congenitally obese and lean rats, fed at two energy intake levels, and analysed at two body weights, to provide eight treatments for regression, with a wide variation in REP and REL. All eight treatments were combined into a common regression, i.e. four parallel regressions, with the implicit assumption that the ME costs of incrementing REP and REL were constant throughout the treatments. Even in this welldesigned study, this latter assumption may not have been accurate, since it was later determined that the fractional rate of protein synthesis was similar in both obese and lean rats, and thus the impaired rate of protein deposition in the obese rats was due to an increased rate of protein degradation and catabolism (Webster et al. 1979). Since protein turnover is an energy demanding process which contributes to $\mathrm{k}_{\mathrm{p}}$ it might be expected that the $\mathrm{k}_{\mathrm{p}}$ pertaining to the obese rats would be lower than that of the lean rats.

Statistical problems with deriving independent estimates of $\mathrm{k}_{\mathrm{f}}$ and $\mathrm{k}_{\mathrm{p}}$ are often attributed to autocorrelation between the variables ME, REP and REL (Rattray et al. 1974; Koong, 1977; Emmans, 1994; Noblet et al. 1999; Knap, 2000), but this is not entirely accurate. Autocorrelation per $s e$ is not the important issue since causality is not being tested. In any case, most experimental data for partitioning $\mathrm{ME}$ intake reverses the statistical causality of the regression, since, in practice, the dependent variable (ME) is manipulated and the effect on the independent variables (REP and REL) is measured. Nevertheless, autocorrelation is also likely associated with a critical mathematical problem indirectly, since such data often exhibit a high level of multi-collinearity. This problem, which causes numerical instability and inconsistent regression coefficients (Roux et al. 1982), is an intrinsic property of the numerical values of the variables, and is not directly related to any aspect of how these quantities were derived. It occurs when data points are not sufficiently linearly independent, so that the slope of the regression plane cannot be properly determined in two independent directions. For practical reasons, multicollinearity in data generated for partitioning of ME intake is difficult to avoid, and the extent of the problem cannot easily be assessed, but it can generally be assumed to be associated with regressions that have large standard errors and (or) unexpected and unstable regression coefficients.

\section{Net energy systems}

NE is traditionally defined (e.g. Knox, 1979) as NE = $\mathrm{ME}-\mathrm{HI}$, where HI is the heat increment of feeding (Fig. 1). It can be further subdivided according to $\mathrm{NE}=\mathrm{NEm}+$ NEp, where NEm is NE for maintenance, and NEp is the gross energy content of animal products. These concepts have been applied to develop practical NE systems (Schiemann et al. 1972; Just, 1982; Noblet et al. 1994a) which use empirical observations to estimate the useful energy an animal can acquire from the diet as a function of the nutrient composition of the diet. Such NE systems can effectively account for the differences in energetic efficiency related to nutrient energy source by considering its impact on the heat increment, however, as for the ME model, the statistical relationships governing response cannot associate energy requirements with the functional biological processes that use the energy. Specific limitations of static NE systems relate to: (1) estimation of NEm; (2) the experimental and analytical methodology for determining NE values (see p. 656); (3) an inability to reflect variation in the metabolic use of energy.

The estimate of NEm will generally not affect the prediction of the relative ranking of diet NE content (Noblet \& Henry, 1991; Noblet et al. 1994a), but, if this is the only objective of an NE system, diet ranking may just as well be accomplished by defining NE as RE and ignoring NEm altogether. The absolute NE value for a particular diet, and therefore the predicted energetic efficiency NE/ME for that diet, will be directly affected by the value used to represent NEm.

$\mathrm{NE}$ for maintenance cannot be determined directly by experimental means. Therefore NE systems must estimate NEm, for which BMR, the equilibrium HP of a fasting animal is often used. BMR itself cannot be measured directly experimentally, and is generally estimated by one or more measurements of fasting HP, which approaches BMR asymptotically in time (Schiemann et al. 1972; Just, 1982; Noblet \& Henry, 1991; Noblet et al. 1989a, 1994a,b). BMR is not a good estimate for NEm, since it represents both the energy requirements for basal body functions, which may be represented by ATP requirements at the cellular level, as well as heat produced by generating ATP from body nutrient stores (Fig. 2). It is more appropriate to represent NEm as $k_{b} \times B M R$, where $k_{b}$ is the efficiency of converting energy retained in body nutrients to useful energy contained in ATP. In a similar manner, NEm may be calculated from MEm as $k_{d} \times M E m$, where $k_{d}$ is the efficiency of utilizing dietary energy sources for generating ATP. The value $\mathrm{k}_{\mathrm{m}}=$ $\mathrm{k}_{\mathrm{d}} / \mathrm{k}_{\mathrm{b}}$ is simply the relative efficiency of using body as compared with dietary nutrients, i.e. it is the BMR:MEm 


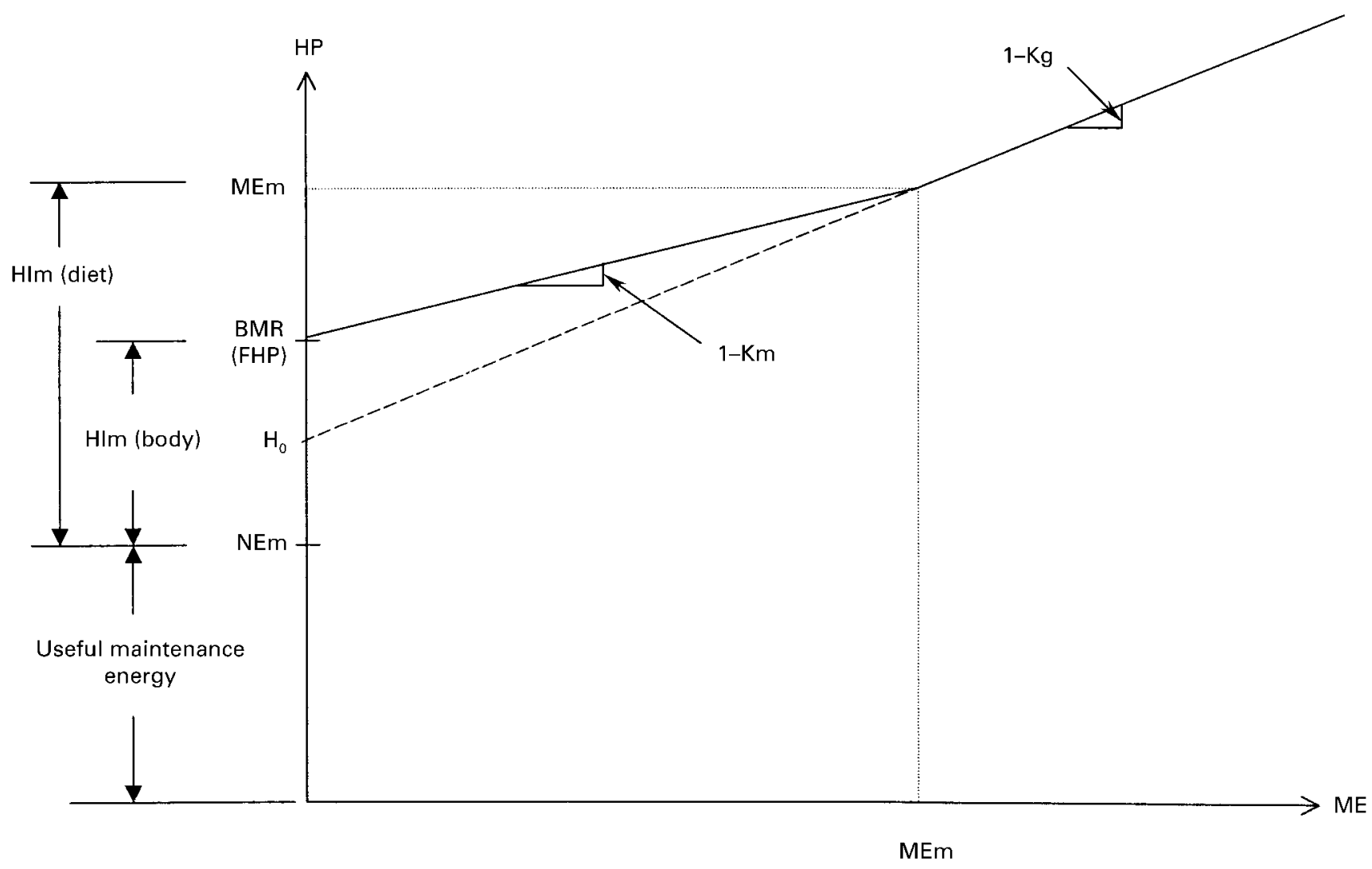

Fig. 2. General representation of the relationship between heat production (HP) and metabolizable energy intake (ME). Maintenance ME (MEm) is defined as the ME intake MEm for which HP = MEm. BMR is equilibrium fasting HP (FHP). Maintenance net energy (NEm) is the useful energy required for basal purposes. NEm may be supplied from nutrients in dietary intake, with heat increment $\mathrm{HIm}$ (diet) and marginal energetic efficiency $\mathrm{k}_{\mathrm{d}}$, or from body nutrient stores, with heat increment HIm(body) and marginal energetic efficiency $\mathrm{k}_{\mathrm{b}}$. At intakes above $M E m$, energy is retained (RE), with heat increment of feeding $\mathrm{HI}$ and efficiency $\mathrm{k}_{\mathrm{g}}$. $\mathrm{H}_{0}$ is the extrapolated intercept from the HP $v$. ME relationship above MEm.

ratio. A strong conceptual relationship exists between fasting HP and NEm, since $\mathrm{k}_{\mathrm{b}}$ is likely to vary little, which follows because the relative contribution of body nutrients for generating ATP in a starved animal is likely to vary little, although it may be influenced by nutritional history (e.g. Koong et al. 1982). The relationship between MEm and NEm is weaker, since $\mathrm{k}_{\mathrm{d}}$ is influenced by diet nutrient composition.

As an alternative to experimental measurement of fasting HP, Noblet et al. (1989a, 1994a) estimate fasting HP by extrapolating a linear relationship between HP and ME above maintenance (with slope $1-\mathrm{k}_{\mathrm{g}}$ ) to its zero-ME intercept $\left(\mathrm{H}_{0}\right)$. However, there is apparently no relationship between FHP $=\mathrm{k}_{\mathrm{m}} \times$ MEm and $\mathrm{H}_{0}=\mathrm{k}_{\mathrm{g}} \times$ MEm (Fig. 2), because there is none between $\mathrm{k}_{\mathrm{m}}$ and $\mathrm{k}_{\mathrm{g}}$ (Blaxter \& Wainman, 1961; Fowler et al. 1979; Webster, 1989; Emmans, 1994). In some situations $\mathrm{H}_{0}$ may actually provide a better direct estimate of NEm than BMR, when $\mathrm{H}_{0}$ is smaller than BMR, but this relationship is unpredictable and depends on the relative values of $\mathrm{k}_{\mathrm{b}}, \mathrm{k}_{\mathrm{d}}$, and $\mathrm{k}_{\mathrm{g}}$. The intercept $\mathrm{H}_{0}$ is difficult to determine accurately in practice and is particularly sensitive to the slope of the regression from which it is extrapolated. The relationship between HP and ME must be established for the reasonably narrow range of intakes in which a theoretical linear relationship can be expected, i.e. above that for which lipid retention is nonnegative, about 1.3 times MEm for pigs (de Greef, 1992), and below that for which protein retention has reached the maximum potential protein retention, about $2.5 \times \mathrm{MEm}$ for pigs (de Greef, 1992). In this ME range, $\mathrm{k}_{\mathrm{g}}$ will vary both with diet composition and according to the REP:REL ratio in the incremental gain. For a fixed composition of the gain (Fig. 3), the intercept $\mathrm{H}_{0}$ is largely independent of diet composition, since $\mathrm{H}_{0}=\mathrm{k}_{\mathrm{g}} \times \mathrm{MEm}=\left(\mathrm{k}_{\mathrm{g}} / \mathrm{k}_{\mathrm{d}}\right) \times \mathrm{NEm}$, and the $\mathrm{k}_{\mathrm{g}}: \mathrm{k}_{\mathrm{d}}$ ratio is based on relative biochemical and biological efficiencies of generating REL, REP and ATP $\left(\mathrm{k}_{\mathrm{g}}\right)$, or ATP alone $\left(\mathrm{k}_{\mathrm{d}}\right)$, from dietary nutrients. Conceptually, this implies that both MEm and $\mathrm{k}_{\mathrm{g}}$ should change with diet composition in such a way that the product is constant, demonstrating the dependence of MEm on diet composition as well as the animal's state. In contrast, for variation in $\mathrm{k}_{\mathrm{g}}$ that is related to differences in the incremental REP:REL ratio, and a fixed diet composition (with no associated change in $\mathrm{k}_{\mathrm{d}}$ ), the intercept $\mathrm{H}_{0}$ is not a constant (Fig. 4), ranging between the values $\mathrm{k}_{\mathrm{p}} \times \mathrm{MEm}$ and $\mathrm{k}_{\mathrm{f}} \times \mathrm{MEm}$. Thus, for a given diet, the experimental distribution of RE between REP and REL can influence the value determined for $\mathrm{H}_{0}$ by as much as $40 \%$.

This suggests that different $\mathrm{k}_{\mathrm{g}}$ values and regression lines can be expected for HP $v$. ME observations that pertain to 


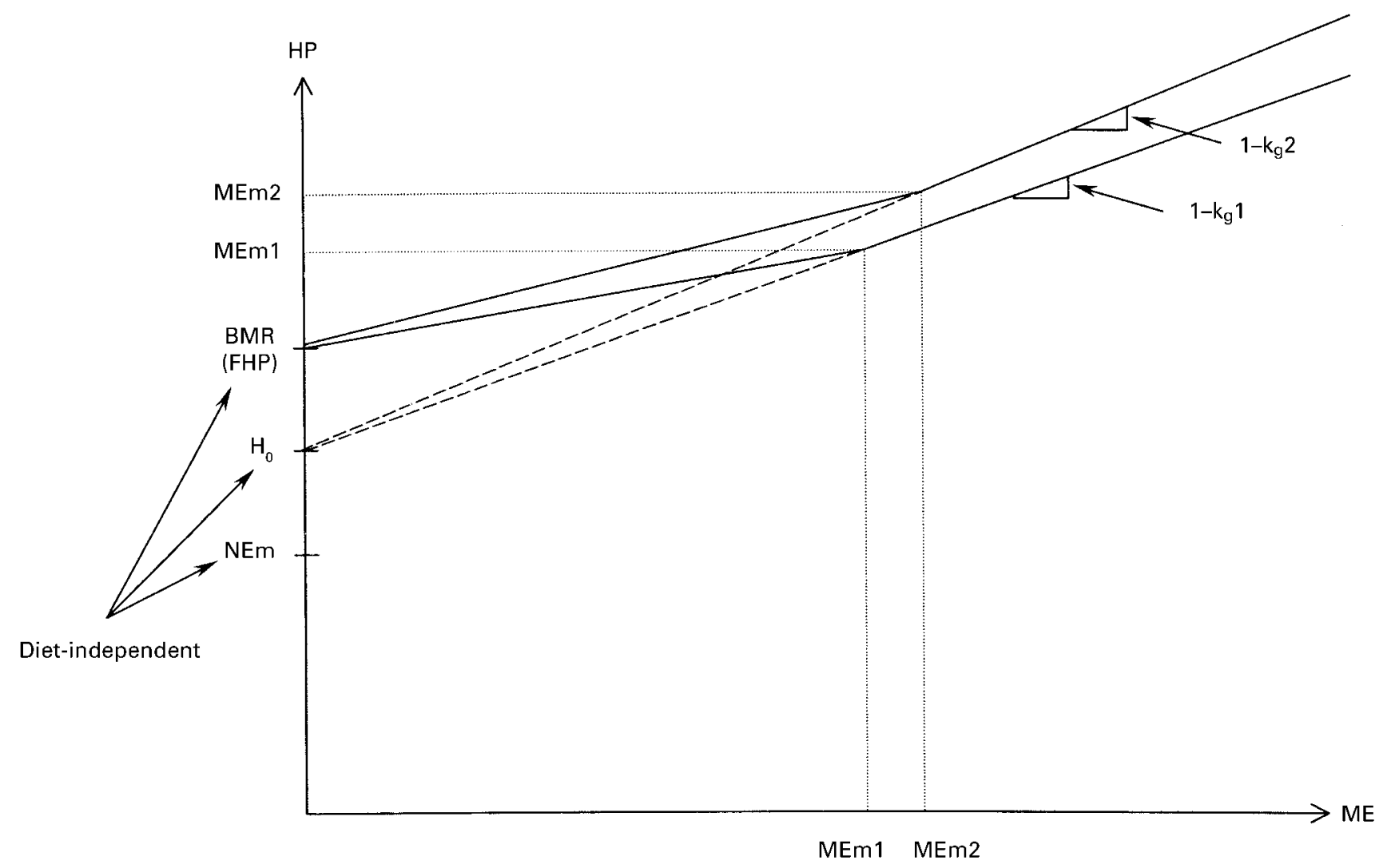

Fig. 3. General representation of the relationship between heat production (HP) and metabolizable energy intake (ME) for different diet compositions with fixed composition of gain. BMR, i.e. equilibrium fasting heat production (FHP), extrapolated intercept $\left(\mathrm{H}_{0}\right)$, and maintenance net energy $(\mathrm{NEm})$ are diet-independent. Maintenance ME intake $(\mathrm{MEm})$ varies with marginal energetic efficiency $\left(\mathrm{k}_{\mathrm{g}}\right)$ of using ME for energy retention (RE), in such a way that $\mathrm{H}_{0}=\mathrm{k}_{\mathrm{g}} \times \mathrm{MEm}$ is constant.

different diet compositions and REP:REL ratios. To derive a value for $\mathrm{H}_{0}$, observations for different diets can be kept separate, in which case a reasonable number of different ME intake levels must be available for each diet. Alternatively, the intercept of a combined regression with observations from different diets can be used to approximate the common convergence point of the individual regressions (Noblet et al. 1994a). With an adequate number of diets and range of ME values, the combined regression can be based on just a single ME value for each diet. However, with such a combined regression, to avoid a biased value for $\mathrm{H}_{0}$, it is critical that ME intakes and diet composition be independent, i.e. there must be no correlation between ME intakes and the $\mathrm{k}_{\mathrm{g}}$ values for individual diets.

Regardless of how well an NE system predicts variation in energetic efficiency related to diet nutrient composition, it is very limited in its representation of animal effects on energy utilization. For example, energetic efficiencies, and also the hierarchy of relative efficiencies, are affected by the metabolic use of nutrients, i.e. for maintenance, lipid and protein retention, milk production, and so on (Noblet, 1996; Whittemore, 1997). Other animal effects on NE include: alternative metabolic pathways for energy substrates with different efficiencies; variation in the utilization of amino acid intake; variation in faecal excretion related to nutrient digestibility; and variable rates of fermentation $v$. enzymatic digestion for particular nutrients. These metabolic effects on energetic efficiency are not insignificant. For example: $\mathrm{k}_{\mathrm{g}}$ for a typical pig diet might vary from 0.60 to 0.65 simply as a consequence of varying the REL:REP ratio in the incremental gain from 1 to 3 ; a change in the relative proportion of maintenance to production, as might be influenced by live weight for instance, will have a similar effect on $\mathrm{k}_{\mathrm{g}}$; and lipid retention from dietary as compared with de novo fatty acid sources will involve significantly different energetic efficiencies, for instance $90 \%$ v. $75 \%$ for pigs (Black, 1995). Since the NE content which characterizes a diet can pertain to only one particular (average) metabolic state, none of these effects can be incorporated in an NE system.

To illustrate the problems involved with the derivation and interpretation of NE values, the NE system for pigs presented in Noblet et al. $(1989 a, 1994 a)$ is examined. This system is based on the results of an extensive series of complex feeding trials involving a total of sixty-one experimental diets of widely varied composition, fed to pigs at two levels of ME intake, with a total of 480 observations of HP in individual pigs. Target high-ME intake level was $2.43 \mathrm{MJ} / \mathrm{kg}$ body weight ${ }^{0.60}$. However, due to feed refusals for some of the high-fibre diets, these were not always achieved (reported mean $2.26 \mathrm{MJ} / \mathrm{kg}$ body weight ${ }^{0.60}$, range $1.95-2.69 \mathrm{MJ} / \mathrm{kg}$ body weight ${ }^{0.60}$ ) and the actual high-ME intake levels corresponded to a range of 64-88\% ad libitum intake according to National Research Council (1987). 


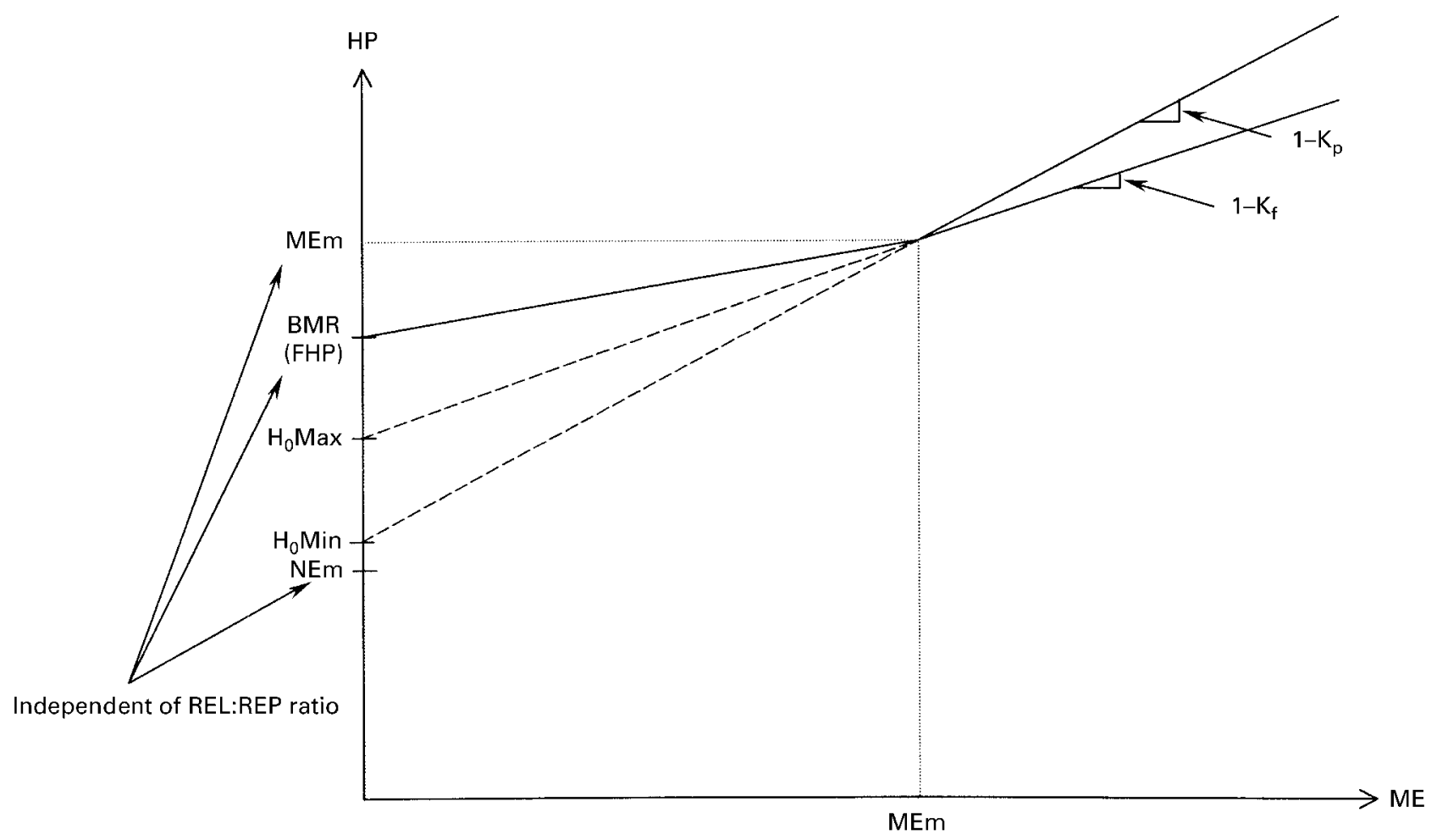

Fig. 4. General representation of the relationship between heat production (HP) and metabolizable energy intake (ME) for fixed diet composition and varying composition of gain. BMR, i.e. equilibrium fasting heat production (FHP), maintenance net energy (NEm), and maintenance ME intake $(\mathrm{MEm})$ are independent of the lipid $(\mathrm{Ld})$ :protein $(\mathrm{Pd})$ ratio in the gain. The extrapolated intercept $\left(\mathrm{H}_{0}\right)$ depends on the Ld:Pd ratio, varying from $k_{p} \times N E m$ to $k_{f} \times N E m$, where $k_{p}$ and $k_{f}$ are the marginal energetic efficiencies of using ME for protein and lipid retention respectively. REL, retained energy from lipid; REP, retained energy from protein.

Low intake level was restricted to $60 \%$ of the target high intake level. Gross energy content and faecal nutrient and energy digestibilities, as well as urinary and gaseous energy losses, were determined for each of the diets, and ileal digestibilities were measured for some nutrients. During each treatment period of 3 weeks, a diet was fed at the low intake level on days 19 and 20, and otherwise at the high intake level. $\mathrm{N}$ balance was measured on days 11-18; HP was measured by indirect calorimetry methods (Brouwer equation) on days 15 to 18 (high intake) and on day 20 (low intake). For each diet, $\mathrm{NE}=\mathrm{H}_{0}+\mathrm{RE}$ was calculated using the high intake level RE observations, and an estimate for $\mathrm{H}_{0}$ extrapolated from a linear regression based on the combined HP $v$. ME observations at the high and low intake levels, together with some additional observations from a small independent dataset (Noblet et al. 1989b; n 30, ad libitum maize-soyabean meal-fed boars). Despite a rigorous and sophisticated experimental methodology, several problems may have distorted the analytical aspects of the study, and the general applicability of the NE equations derived can be questioned:

1. a diet quality bias is evident in the high intake level observations, probably related to the variation in intake resulting from feed refusals. Analysis of the reported values shows a significant positive correlation between diet quality, defined in terms of DM digestibility, and ME intake/body weight ${ }^{0.6}$. This association of the less energy-efficient diets with the lower ME intakes tends to underestimate the slope of the combined regression for the high intake level observations, and overestimate the intercept, $\mathrm{H}_{0}$;

2. HP was measured after only a single day of feeding a diet at the low intake level. This very short adjustment period was implemented in an attempt to separate HP due to nutrient metabolism, e.g. biochemistry, from that due to biological processes, e.g. maintenance energy requirements (J Noblet, personal communication). However, as a result, the HP values at the low intake level are likely significantly higher than equilibrium HP would have been at these ME intakes (see p. 650). In the combined regression, these low intake level observations will compound the effect on the slope due to the diet quality bias, with an additional tendency to overestimate the intercept, $\mathrm{H}_{0}$;

3. the extent of variation reported for the REL:REP ratio at the high intake level, between about 1.0 and 2.5, was considered not to significantly affect the NE values obtained (Noblet et al. 1989a, 1994a), however this assessment is based on estimates for $\mathrm{k}_{\mathrm{p}}$ and $\mathrm{k}_{\mathrm{f}}$ of 0.6 and 0.8 (Noblet et al. 1989b, 1991). Alternative estimates for $\mathrm{k}_{\mathrm{p}}$ and $\mathrm{k}_{\mathrm{f}}$ of 0.48 and 0.72 , more typical of the literature values cited earlier, would imply a larger variation in $\mathrm{k}_{\mathrm{g}}$, by up to $10 \%$, due to the reported variation in REL:REP ratio. This affects the estimate of $\mathrm{H}_{0}$ in the combined regression, the interpretation of the NE values for a particular diet, and the relative efficiency predicted for different diets. 
These points demonstrate that practical problems with NE systems are difficult to avoid, even when these are based on an extensive and comprehensive series of experiments. To determine simultaneously the energetic consequences of diet nutrient source, metabolic use of nutrient intake, and metabolic pathway, an alternative, more mechanistic model is required. As suggested by Noblet \& Henry (1991): 'on a long term basis, progress in pig nutrition will come from mechanistic approaches where both the animal's requirement and dietary nutrient utilization will be considered in a biochemical and regulatory approach.'

\section{Representing energy utilization by nutrient flows}

To avoid the limitations associated with ME or NE models of energy utilization, a more biologically meaningful model is suggested using a systems approach to represent explicitly the material flows of nutrients and the transformations these undergo as they are processed by an animal. In modelling animal nutrition six functionally distinct biological processes (Fig. 5) can be identified: $I$, intake, the acquisition of absorbed nutrients; $M$, metabolic, the conversion of absorbed nutrients to anabolic and energy-yielding substrates; $f X$, faecal excretion of non-digested and endogenous material; $u X$, urinary excretion of non-metabolizable and endogenous material; $P$, production, the synthesis of animal products, and their retention or secretion; and $B$, basal nutrient expenditure, the residual nutrient requirements not accounted with the other processes. Free energy, supplied by $M$ in the form of ATP bonds, is required to drive each of these transformation processes. According to the animal species, the production objective, and the purpose of the model, the internal structure of each process can be expanded to an appropriate level of detail necessary to predict input-output response at the whole-animal level adequately, based on causal relations associated with the functional biological and biochemical principles represented.

This nutritional process model representing explicit nutrient flows is conceptually consistent with conventional approaches to modelling energy utilization, which can be derived from it by converting nutrient flows to equivalent energy flows using the corresponding energy densities, and regarding the nutrient transformation processes simply as energy transformations (filters). For example, the ME model consists of the energy filters: $I$ from gross energy to digestible energy; $M$ from digestible energy to $\mathrm{ME} ; P$ from ME to animal products; and $B$ from ME to MEm. The equations that represent these energy filters (e.g. in terms of $\mathrm{k}_{\mathrm{p}}, \mathrm{k}_{\mathrm{f}}$, and so on) reflect the combined energetic consequences of biochemical and biological inefficiencies, the effects of which cannot therefore be separated.

The concept of 'effective energy' (Emmans, 1994) provides a valuable extension of the ME model by explicitly allocating some ME intake to faecal and urinary excretion, i.e. to drive the two material waste flows. In effect two additional energy filters have been included in this effective energy model, $f X$ and $u X$, providing a closer association of biological processes with the heat production for which they are responsible, and a metabolically improved model compared with the conventional ME or NE approach. However, effective energy still has the limitation of an empirical (i.e. statistical), rather than causal, input-output response. Moreover, diet nutrient composition is only partially taken into account by using different efficiencies for direct and de novo fat deposition for monogastric animals, or the factor related to the efficiency of fermentation for ruminant animals.

The theoretical conceptual framework for this nutritional process model reflects the conventional biological view of

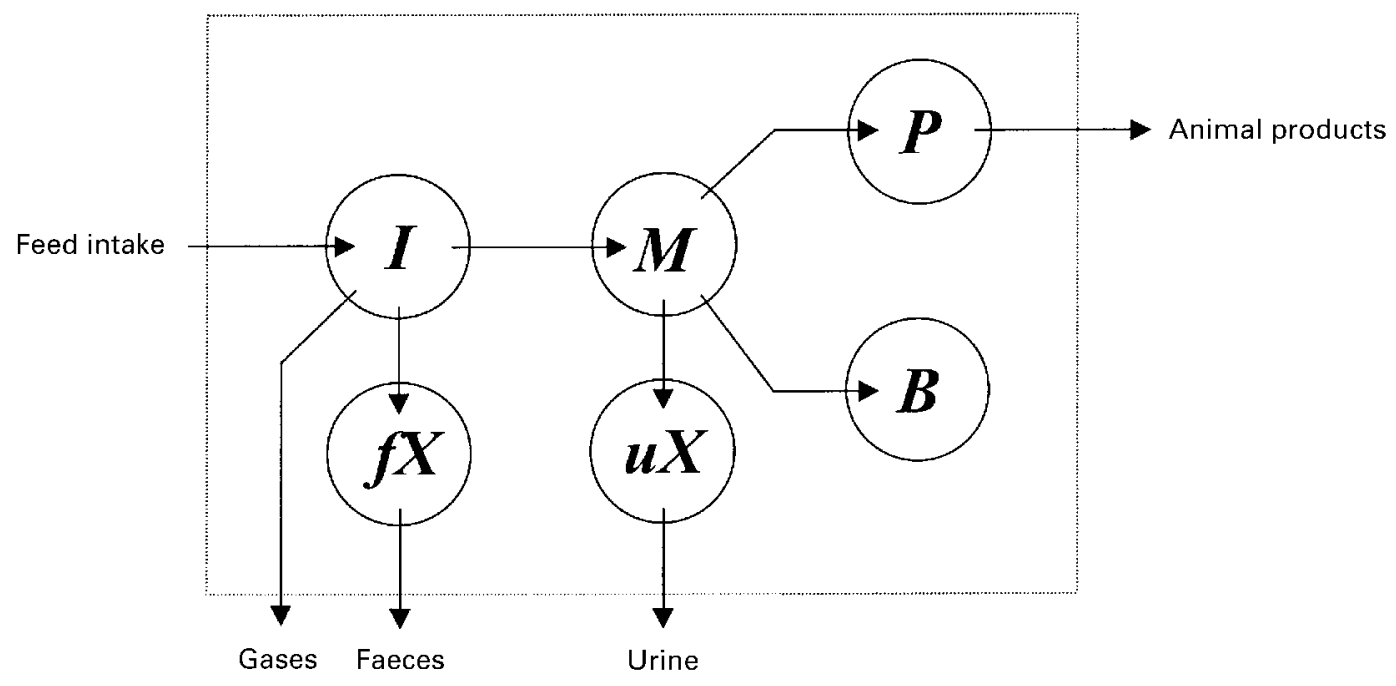

Fig. 5. Nutritional process model of nutrient utilization based on nutrient flows. Material flows of nutrients and metabolites, and the main material transformations between these (nutritional processes) are explicitly represented. Feed intake is converted in $I$ (intake process) into absorbed nutrients, from which $M$ (metabolic process) acquires energy yielding metabolites and anabolic substrates. These are converted by $P$ (production process) into animal products which are either retained or secreted. The residual nutrient requirements not explicitly included elsewhere are represented by $B$ (basal process). Excretion of waste products is represented by $f X$ (faecal excretion process) and $u X$ (urinary excretion process). These nutritional processes require free energy, which is supplied from $M$ in the form of ATP. Heat production can be attributed directly to the biological and biochemical processes with which it is associated. 
animal nutrition and metabolism (Baldwin \& Bywater, 1984). The control rules which govern model input-output response by choosing a unique metabolic pathway for nutrients are based on phenomenological observations at the whole-animal level. Metabolic flows are not used for control purposes (as they are in a mechanistic biochemical model), only for the material bookkeeping required to represent metabolic effects on the energetic efficiency of nutrient utilization. Model variables must therefore be defined as the average flows of nutrients over some time period $\tau$ consistent with the whole-animal observations on which the control rules are based. For example, average daily nutrient flows $(\mathrm{g} / \mathrm{d}$ or $\mathrm{mol} / \mathrm{d}$ ) would be appropriate in an animal growth model; for modelling milk production in dairy cows, nutrient flows might be averaged over a time period in $\mathrm{min}$ (e.g. $\mathrm{mmol} / \mathrm{min}$ ).

The primary model input consists of feed intake expressed as the total mass of feed consumed per time period $\tau$, and characterized according to specific nutrient flows. Only those nutrient intakes $X_{1}, \ldots, X_{n}$ which are relevant to the species and production application being modelled need be explicitly represented; flows of other materials can be implicitly associated with the flows $\mathrm{X}_{1}, \ldots, \mathrm{X}_{\mathrm{n}}$. For example, water and ash might be regarded as implicit nutrients, and the flow of organic matter considered to be the model input. Since only the main material flows and biological processes are explicitly represented, some of the energy requirements for these transformations can be attributed to the material flows that are implicitly associated with them. Model outputs consist of wastes (faeces, gases, and urine) and secreted animal products (e.g. milk, eggs). Material transformation processes convert the input nutrient flows $X_{1}, \ldots, X_{n}$ into flows of other nutrients (e.g. volatile fatty acids, glucose etc.) and metabolites (e.g. acetyl Co-A, ATP), which serve as the anabolic substrates for the products and a source of free energy. In general, an explicit chemical mass balance is not achieved (e.g. for C), however, it may be desirable to choose explicit material flows carefully so this is ensured in some cases, for example when it is metabolically important or relevant in environmental applications (e.g., N, P).

\section{A nutritional process model for growing animals}

To illustrate the concepts, a model is described for nutrient utilization by growing animals, for which the products are retained protein and lipid determined on a daily basis. This model extends the representations of nutrient utilization used in conventional animal growth models (e.g. Whittemore \& Fawcett, 1976; Agricultural Research Council, 1981; Black et al. 1986; Moughan et al. 1987; Technisch Model Varkensvoeding, 1991; de Lange, 1995). Daily DM intake can be characterized by the explicit flows of essential amino acids, NSN, crude fat, starch, sugars, and remaining organic material, largely NSP. All other material flows are regarded as implicit. For example, ash flow and its retention is not represented, therefore it must be implicitly linked to the flow of some other material(s), likely retained body protein with which it can be biologically associated. Waste outputs are non-digested DM (xDM) and uN. N flows are represented in sufficient detail to achieve a mass $\mathrm{N}$ balance.
The control structure for nutrient utilization must determine a unique pathway for each material flow, according to the animal's metabolic state. Nutrient use is prioritized as follows: (1) a basal requirement for amino acids and ATP independent of production level; then (2) the potential protein retention consistent with the remaining available amino acid intake and the animal's (genetic) performance potential; and, finally (3) daily lipid retention as the sink for excess nutrient intake, based on the constraint of a mass balance for individual metabolite flows. Phenomenological controls such as this can be made quite sophisticated, for example by incorporating additional constraints on the chemical composition of growth to force a minimum body lipid:body protein retention ratio.

The intake process represents the physical ingestion of (digestible) nutrient intake, and its transformation by digestion, absorption, and transport to sites for metabolic utilization. Intake requires free energy to support the physical work of processing the material, and for the biochemical and physical changes which the nutrients undergo. In general, two distinct subprocesses are required, representing the biological processes of enzymatic digestion and fermentation. A complex submodel may be necessary for the fermentation process, representing explicitly the various interacting biochemical and microbial processes involved (Dijkstra et al. 1992). However, a simplified representation is likely to be adequate in many cases, for example for monogastric animals (Birkett \& de Lange, 2001a).

The metabolic process either makes absorbed nutrients directly available for use as anabolic substrates (e.g. dietary fatty acids) by the production process, or transforms them biochemically to metabolites which can serve as anabolic or energy-yielding substrates. The products of degraded body protein and lipid may also re-enter the metabolic pools. Subprocesses must be included in $M$ to represent relevant biochemical transformations (e.g. catabolism of amino acids, glucose, and so on). An output of ATP is produced as needed to meet the free energy requirements of the other processes. Waste outputs from $M$ are $\mathrm{N}$ from catabolized amino acids and non-specific losses from the free amino acid pool. Metabolic energy requirements are either implicit in the biochemical inefficiencies expressed in the stoichiometry of the catabolic processes, or expressed as ATP requirements which must be explicitly generated in $M$.

The free energy requirement for faecal excretion is a consequence of the physical work of ingesting, processing, and excreting non-digested material. The free energy requirement for urinary excretion, including $\mathrm{N}$ derived from catabolized amino acids, fermentation, and non-specific losses, also includes an amount which can be attributed to various metabolic processes that are implicitly associated with urinary excretion.

The production process transforms anabolic substrates into animal products, in this case retained body protein and lipid. For growing animals, defining a production rate unambiguously has logical difficulties because retention equilibrium is, in general, a dynamic state. In particular, a state of zero retention is likely to involve non-zero but equal rates of product synthesis and degradation. To attribute energy and material requirements to the correct subprocesses 
where they originate, suggests that, in the most general conceptual model, product synthesis and degradation must be separately and explicitly represented (Whittemore \& Fawcett, 1976). However, various reasons suggest that a simplified model representing only the net production level may have to be adopted in practice (Birkett \& de Lange, $2001 a$ ). In this case only a single material flow from $M$ to $P$ is needed, representing the substrate flow required to support the net production level. The energy requirement to support net retention consists of an incremental amount which can be associated directly with an increment in the net rate of product retention, and a residual amount that can conveniently be included in the basal ATP requirement because it is independent of the rate of production and the other processes.

The basal ATP requirement, that which cannot be associated with feed intake, urinary and faecal excretion, or (net) production, represents the residual energy expenditure which is independent of diet, feeding, and metabolic state. A close connection can therefore be expected to physical body state, with some adjustment for animal type, activity, and environmental factors. Basal free energy requirement (BE) may be supplied (with varying efficiencies) from metabolite sources derived from nutrient intake or via mobilization and catabolism of body tissues. No attempt is made to estimate separately the energy requirements for the various metabolic and physiological processes that contribute to BE (Milligan \& Summers, 1986; Black, 1995), which include: (1) basal visceral protein turnover independent of intake and rate of protein retention, i.e. to maintain a minimum visceral size, the equilibrium size which would be attained after a sufficiently long period of zero nutrient intake; (2) basal carcass protein turnover independent of the rate of production; (3) protein synthesis to replace skin and hair losses and basal endogenous gut losses, i.e. gut losses not associated with intake; (4) basal lipid turnover not related to the rate of lipid retention; (5) maintenance of metabolite pool levels, concentration gradients etc.; (6) minimum respiration, blood flow, muscle tension, activity and immune system function; (7) metabolic processes necessary to derive energy from metabolite pools to meet all the energy requirements mentioned earlier. Protein turnover, especially that in the visceral organs, and the associated activity of $\mathrm{Na}^{+} / \mathrm{K}^{+}$pumps are likely the main contributors to BE (Milligan \& Summers, 1986; Gill et al. 1989; Yen, 1997), therefore it is not unreasonable to assume a relationship between $\mathrm{BE}$ and body protein mass.

\section{Discussion and conclusions}

Conventional approaches to represent energy utilization have been discussed and a material flow model described to represent nutrient utilization by animals in a wide range of metabolic and nutritional states. The conversion of dietary nutrient intake to nutrients in animal products is explicitly represented in such a way that the HP associated with the main biochemical and biological processes may be estimated. To represent nutrient utilization properly some level of metabolic detail is necessary, so that 'useful energy' can be separated from heat increments in a functionally and biologically meaningful way. Control rules based on phenomenological whole-animal response can be used to determine the primary nutrient fluxes at the metabolic level. This approach can be contrasted with the control rules for a mechanistic whole-animal biochemical model, for which metabolites play a fundamental role in determining wholeanimal response based on the regulation of metabolite interchanges between pools (e.g. Gerrits, 1996). These two approaches essentially reverse the causality of the control structure of the model. Support for basing control at the whole-animal level is provided by Pattee (1973): 'Many hierarchical structures will arise from the detailed dynamics of the elements ... but the optimum degree of constraint for hierarchical control is not determined by the detailed dynamics of the elements. The dynamics of control is determined by how these details are ignored. In other words, hierarchical controls arise from a degree of internal constraint that forces the elements into a collective, simplified behaviour that is independent of selected details of the dynamic behaviour of its elements.'

It is not feasible for an $\mathrm{ME}$ (digestible energy), or $\mathrm{NE}$ model to represent differences in efficiency resulting from the combined effects of various factors which contribute to them: (1) ingestion, digestion, and absorption of digestible nutrients; (2) ingestion and faecal excretion of nondigestible materials; (3) biochemical conversion of nutrients to ATP and animal products; (4) urinary excretion of nutrients that cannot be metabolized; (5) synthesis of animal products, and retention and (or) secretion. These are incorporated to varying extents in the conventional models of energy utilization by animals. The digestible energy approach is the simplest and explains the greatest extent of variation in the useful energy which can be derived from nutrient intake, however variation arising from digestion and metabolism is not taken into account. The ME system considers the energy physically lost through urinary excretion, but not the energy required to drive that excretion. Furthermore, estimates of $\mathrm{N}$ excretion used to define ME are at best only approximations and cannot account for the varying metabolic status of the animal. In an NE system the effects of both biochemical inefficiency and dietary energy density are implicitly represented in the statistical relationships which define $\mathrm{NE}$ as a function of diet composition (e.g. Noblet et al. 1994a). However, the objective of an NE system, i.e. estimating the useful energy which can be derived from a nutrient source, cannot be achieved completely because NE equations make no allowance for variation in the metabolic state of an animal. The effective energy concept of Emmans (1994) includes the energetic costs of faecal and urinary excretion, but the combined effects of other sources of inefficiency are still represented by statistically derived energetic efficiencies. Biological and biochemical energetic efficiencies are naturally represented in the nutritional process model which closely associates the main energy requirements with the biological processes which incur them.

Although the purpose of the nutritional process model is to predict the utilization and partitioning of nutrient intake in animals without explicit consideration of energy flows, it is possible to generate the implied energy flows calculated from a model outputs. In this case the nutritional process model becomes a mechanistic net energy model which can 
take full account of both the source and metabolic use of nutrients. This provides a means for calculating the NE densities of diets in terms of their nutrient composition, for particular defined metabolic states. BE, independent of both diet nutrient composition and metabolic state, is conceptually very close to the classical definition of NEm and may be used to represent that term in the definition of $\mathrm{NE}=$ $\mathrm{BE}+\mathrm{RE}$. Model-generated NE densities can provide a powerful means for quantitatively comparing and ranking diets under specified metabolic conditions.

A general conceptual framework has been presented for modelling animal nutrition based on qualitatively accurate and biologically meaningful principles. To use the model for simulation of commercial animal production requires accurate prediction of quantitative response for specific animals and conditions (de Lange et al. 2001). Such a predictive model will generally be more robust, i.e. extrapolated accurately and easily to different situations, if it is based on a flexible and biologically meaningful underlying conceptual structure, such as the nutritional process model presented above, rather than on ad hoc or statistical relationships. This application requires the development of a detailed computational structure for the various subprocesses that determine the input-output response of the main biological and biochemical transformations. This includes the selection of a relevant set of explicit nutrient flows, represented as average flows over a time period consistent with the whole-animal observations that determine the control rules which differentiate between competing metabolic pathways for nutrients. A computational structure applicable to growing monogastric animals is described by Birkett \& de Lange (2001a), and a detailed calibration procedure for adjusting the marginal and absolute response of this model is described by Birkett $\&$ de Lange (2001b), and applied to parameterize a practical model for nutrient utilization by pigs. The nutritional process model should improve the accuracy of predictions of energy utilization for diets with varying nutrient compositions, under a wide range of animal metabolic conditions and production levels. In addition to this representation of energy utilization, a complete practical model representing animal production would require several other steps: (1) detailed representation of amino acid utilization and requirements for production and support; (2) control rules for partitioning nutrient intake beween lipid, protein, and carbohydrate, e.g. lactose in lactating animals, in animal products; (3) relationships between body chemical and physical composition; (4) an additional calibration adjustment so the predictions for particular practical, e.g. on-farm, conditions are accurate.

\section{Acknowledgements}

Sincere appreciation is given for the financial support of Agribrands International for the research related to this article. The authors would like to thank Paul Moughan, Martin Verstegen, Patrick Morel and Bruno Marty for their contributions to the development of the concepts. Valuable discussions with Jean Noblet are also gratefully appreciated.

\section{References}

Agricultural Research Council (1981) The Nutrient Requirements of Pigs. London: Commonwealth Agricultural Bureaux.

Azevedo PA, Cho CY, Leeson S \& Bureau D (1998) Effects of feeding level and water temperature on growth, nutrient and energy utilization and waste output of rainbow trout (Oncorhynchus mykiss). Aquatic Living Resources 11, 227-238.

Baldwin RL \& Bywater AC (1984) Nutritional energetics of animals. Annual Review of Nutrition 4, 101-114.

Baldwin RL, France J \& Gill M (1987) Metabolism of the lactating cow I: animal elements of a mechanistic model. Journal of Dairy Research 54, 77-105.

Bernier JF, Dubois S \& Noblet J (1996) Fasting heat production of Large White and Meishan growing pigs as influenced by environmental temperature. Journal of Animal Science 74, Suppl. 1, 180.

Bikker P (1994) Protein and lipid accretion in body components of growing pigs: effects of body weight and nutrient intake. $\mathrm{PhD}$ Thesis, Wageningen Agricultural University.

Birkett S \& de Lange K (2001a) A computational framework for a nutrient flow representation of energy utilization by growing monogastric animals. British Journal of Nutrition 86, 661-674.

Birkett S \& de Lange K (2001b) Calibration of a nutrient flow model of energy utilization by growing pigs. British Journal of Nutrition 86, 675-689.

Black JL (1995) Modelling energy metabolism in the pig - critical evaluation of a simple reference model. In Modelling Growth in the Pig, EAAP Publication no. 78, pp. 87-102 [PJ Moughan, MWA Verstegen and MI Visser-Reyneveld, editors]. Wageningen: Wageningen Pers.

Black JL, Campbell RG, Williams IH, James K \& Davies GT (1986) Simulation of energy and amino acid utilization in the pig. Research and Development in Agriculture 3, 121.

Blaxter KL \& Wainman FW (1961) The utilisation of food by sheep and cattle. Journal of Agricultural Science 57, 419-425.

Buchanan-Smith J \& Fox D (2000) Feeding systems for beef cattle. In Feeding Systems and Feed Evaluation Models, pp. 129-154 [M Theodoro and $\mathrm{J}$ France, editors]. Wallingford: CABI International.

Carr J, Pearson R, Adam J \& Townsley R (1979) The Growth of the Pig. Palmerston North: Massey University.

Centraal Veevoeder Bureau (1998) Veevoedertabel (Table of Feeding Value of Animal Feed Ingredients). Lelystad: Centraal Veevoeder Bureau.

Cho CY \& Bureau D (1998) Development of bioenergetic models and the Fish-PrFEQ software to estimate production, feeding ration, and waste output in aquaculture. Aquatic Living Resources 11, 199-210.

Close WH, Berschauer F \& Heavens R (1982) The influence of protein:energy value of the ration and level of feed intake on the energy and nitrogen balance of the growing pig. British Journal of Nutrition 49, 255-269.

Close WH, Mount L \& Brown D (1978) The effects of plane of nutrition and environmental temperature on the energy metabolism of the growing pig 2. Growth rate, including protein and fat deposition. British Journal of Nutrition 40, 413-431.

Close WH, Verstegen MW \& Mount L (1973) Proceedings of the Nutrition Society 32, 72A.

de Greef KH (1992) Prediction of production: nutrition induced partitioning in growing pigs. $\mathrm{PhD}$ Thesis, Wageningen Agricultural University.

de Lange CFM (1995) Framework for a simple model to demonstrate principles of nutrient partitioning for growth in the pig. In Modelling Growth in the Pig, EAAP Publication no. 78, 
pp. 71-86 [PJ Moughan, MWA Verstegen and MI VisserReyneveld, editors]. Wageningen: Wageningen Pers.

de Lange CFM, Marty B, Birkett SH \& Szkotnicki B (2001) Application of pig growth models in commercial pork production. Canadian Journal of Animal Science 81, 1-8.

Dijkstra J, Neal H, Beever D \& France J (1992) Simulation of nutrient digestion absorption, and outflow in the rumen: model description. Journal of Nutrition 122, 2239-2256.

Emmans GC (1994) Effective energy: A concept of energy utilization applied across species. British Journal of Nutrition 71, 801-821.

Fowler WR, Fuller MF, Close WH \& Whittemore CT (1979) The energy requirements for the growing pig. In Energy Metabolism, Proceedings of the Eighth Symposium on Energy Metabolism, Cambridge, September, 1979, pp. 169-174 [L Mount, editor]. London: Butterworths.

Fuller M, Webster A, MacPhearson R \& Smith J (1976) Comparative aspects of the body metabolism of Pietrain and Large White $\times$ Landrace pigs during growth. In Energy Metabolism of Farm Animals, EAAP Publication no. 19, pp. 177 [M Vermorel, editor]. Clermont-Ferrand: G. de Bussac.

Gerrits W (1996) Modelling the growth of preruminant calves. $\mathrm{PhD}$ Thesis, Wageningen Agricultural University.

Gill J, Thornley J, Black J, Oldham J \& Beever D (1984) Simulation of the metabolism of absorbed energy-yielding nutrients in young sheep. British Journal of Nutrition 52, 621-649.

Gill M, France J, Summers M, McBride B \& Milligan L (1989) Simulation of the energy costs associated with protein turnover and $\mathrm{Na}+\mathrm{K}+$ transport in growing lambs. Journal of Nutrition 119, $1287-1299$.

Hawk PB (1965) Urine: quantitative analysis. In Physiological Chemistry, 14th ed., chapter 31, pp. 1206-1215 [BL Oser, editor]. New York, NY: McGraw-Hill.

Hoffmann L \& Klein M (1980) Die Abhaengigkeit der Harnenergie vom Kohlenstoff- und Stickstoffgehalt in Harn bei Rindern, Schafen, Schweinen und Ratten (The dependency of urinary energy on carbon and nitrogen content of urine in cattle, sheep, pigs and rats). Archiv für Tierernährung 30, $743-750$.

Hruby M, Hamre M \& Coon C (1994) Growth modelling as a tool for predicting amino acid requirements of broilers. Journal of Applied Poultry Research 3, 403-415.

Just A (1982) The net energy value of balanced diets for growing pigs. Livestock Production Science 8, 541.

Kielanowski J (1966) Conversion of energy and the chemical composition of gain in bacon pigs. Animal Production 8, $121-128$.

Kielanowski J (1976) The chemical composition of the live-weight gain and the performance of growing pigs. Livestock Production Science 3, 257-269.

Knap P (2000) Variation in maintenance requirements of growing pigs in relation to body composition. A simulation study. PhD Thesis, Wageningen Agricultural University.

Knox KL (1979) Energy metabolism. In Nitrogen, Electrolytes, Water and Energy Metabolism, vol. 3 of series Comparative Animal Nutrition, chapter 1, pp. 1-13. Basel: S. Karger.

Koong L-J (1977) A new method for estimating energetic efficiencies. Journal of Nutrition 107, 1724-1728.

Koong L-J, Nienaber J, Pekas J \& Yen J-T (1982) Effects of plane of nutrition on organ size and fasting heat production in pigs. Journal of Nutrition 112, 1638-1642.

Kyriazakis I, Dotas D \& Emmans G (1993) The effect of breed on the relationship between feed composition and the efficiency of protein utilization in pigs. British Journal of Nutrition 71, 849-859.

Kyriazakis I \& Emmans G (1992) The effects of varying protein and energy intakes on the growth and body composition of pigs. British Journal of Nutrition 68, 603-613.

McCracken K \& McAllister A (1984) Energy metabolism and body composition of young pigs given low-protein diets. British Journal of Nutrition 51, 225-234.

McCracken K \& Rao SD (1989) Protein: energy interactions in boars of high lean deposition potential. In Energy Metabolism of Farm Animals, Proceedings of the Eleventh Symposium, Lunteren, The Netherlands, 18-24 September 1988, EAAP Publication no. 43, pp. 13-16 [Y van der Honing and WH Close, editors]. Wageningen: Pudoc.

Machiels MAM \& Henken AM (1986) A dynamic simulation model for growth of the African Catfish, Clarias gariepinus (Burchell 1822). I. Effect of feeding level on growth and energy metabolism. Aquaculture 56, 29-52.

Milligan L \& Summers M (1986) The biological basis of maintenance and its relevance to assessing responses to nutrients. Proceedings of the Nutrition Society 45, 185-193.

Möhn S \& de Lange CFM (1997) The effect of body weight on the upper limit to protein deposition in a defined population of growing gilts. Journal of Animal Science 76, 124-133.

Möhn S, Gillis AM, Moughan PJ \& de Lange CFM (2000) Influence of dietary lysine and energy intakes on body protein deposition and lysine utilization in the growing pig. Journal of Animal Science 78, 1510-1519.

Moughan PJ, Smith W \& Pearson G (1987) Description and validation of a model simulating growth in the pig $(20-90 \mathrm{~kg}$ liveweight). New Zealand Journal of Agricultural Research 30, $481-490$.

National Research Council (1987) Predicting Feed Intake of FoodProducing Animals. Washington, DC: National Academy Press.

National Research Council (1998) Nutrient Requirements of Swine, 10th ed. Washington, DC: National Academy Press.

Noblet J (1996) Digestive and metabolic utilisation of dietary energy in pigs feeds: comparison of energy systems. In Recent Advances in Animal Nutrition, pp. 207-231 [P Garnsworthy, J Wiseman and W Haresign, editors]. Nottingham: Nottingham University Press.

Noblet J, Fortune H, Dubois S \& Henry Y (1989a) Nouvelles Bases d'Estimation des Teneurs en Energie Digestible, Metabilisable et Nette des Aliments pour le Porc (New Basis for Estimation of Digestible and Metabolizable Net Energy in Swine Feeds). INRA: Station de Recherche Porcines, Saint Gilles: INRA.

Noblet J, Fortune H, Shi XS \& Dubois S (1994a) Prediction of net energy values of feeds for growing pigs. Journal of Animal Science 72, 344-354.

Noblet J \& Henry Y (1991) Energy evaluation systems for pig diets. In Manipulating Pig Production III, Proceedings of the Third Biennial Conference of the Australasian Pig Science Association (APSA), Albury, NSW, November 24-27, 1991, pp. 87-110 [ES Batterham, editor]. Victoria: APSA.

Noblet J, Henry Y \& Dubois S (1987) Effect of protein and lysine levels in the diet on body gain composition and energy utilization in growing pigs. Journal of Animal Science $\mathbf{6 5}$, 717-726.

Noblet J, Karege C \& Dubois S (1989b) Influence of sex and genotype on energy utilization in growing pigs. In Energy Metabolism of Farm Animals, Proceedings of the Eleventh Symposium, Lunteren, The Netherlands, 18-24 September 1988, EAAP Publication no. 43, pp. 57-60 [Y van der Honing and WH Close, editors]. Wageningen: Pudoc.

Noblet J, Karege C \& Dubois S (1991) Influence of growth potential on energy requirements for maintenance in growing pigs. In Energy Metabolism of Farm Animals, EAAP Publication no. 58, pp. 107-110 [C Wenk and M Boessinger, editors]. Zurich: ETH.

Noblet J, Karege C, Dubois S \& van Milgen J (1999) Metabolic 
utilization of energy and maintenance requirements in growing pigs: effect of sex and genotype. Journal of Animal Science 77, $1208-1216$.

Noblet J, Shi XS \& Dubois S (1993) Metabolic utilization of dietary energy and nutrients for maintenance energy requirements in sows: basis for a net energy system. British Journal of Nutrition 70, 407-419.

Noblet J, Shi XS \& Dubois S (1994b) Effect of body weight on net energy value of feeds for growing pigs. Journal of Animal Science 72, 648-657.

Pattee H (1973) The physical basis and origin of hierarchical control. In Hierarchy Theory: The Challenge of Complex Systems, pp. 73-108 [H Pattee, editor]. New York, NY: Braziller.

Pettigrew J, Gill M, France J \& Close W (1992) A mathematical integration of energy and amino acid metabolism of lactating sows. Journal of Animal Science 70, 3742-3761.

Pomar C, Harris D \& Minvielle F (1991a) Computer simulation model of swine production systems: I. Modeling the growth of young pigs. Journal of Animal Science 69, 1468-1488.

Pomar C, Harris D \& Minvielle F (1991b) Computer simulation model of swine production systems: II. Modeling body composition and weight of female pigs, fetal development, milk production, and growth of suckling pigs. Journal of Animal Science 69, 1489-1502.

Pullar JD \& Webster AJ (1977) The energy cost of fat and protein deposition in the rat. British Journal of Nutrition 37, 355-363.

Rattray PV, Garrett WN, Hinman N \& East NE (1974) Energy cost of protein and fat deposition in sheep. Journal of Animal Science 38, 378-382.

Roux CZ, Hofmeyr HS \& Jordaan E (1982) The problem of multicollinearity in the estimation of partial efficiencies of protein and fat by regression methods. In Energy Metabolism of Farm Animals, Proceedings of the Ninth Symposium, Lillehammer, Norway, September 1982, EAAP Publication no. 29, pp. 138-140 [A Eckern and F Sundstol, editors] Aas-Nlh: Agricultural University of Norway.

Schiemann R, Nehring K, Hoffmann L, Jentsch W \& Chudy A (1972) Energetische Futterbevertung und Energienormen (Energetic Assessment of Feeds). Berlin: VEB Deutscher Landwirtschatsverlag.

Schultz AR (1978) Simulation of energy metabolism in the singlestomached animal. British Journal of Nutrition 39, 235-254.

Technisch Model Varkensvoeding (TMV) (1991) Infomatiemodel. Research Report P1.66, Rosmalen: Research Institute for Pig Husbandry.
Tess M (1981) Simulated effects of genetic change upon life-cycle production efficiency in swine and the effects of body composition upon energy utilization in the growing pig. $\mathrm{PhD}$ Thesis, University of Nebraska.

Thorbek G (1967) Studies on the energy metabolism of growing pigs. In Energy Metabolism of Farm Animals, Proceedings of the Fourth Symposium, Warsaw, Poland, September 1967, EAAP Publication no. 12, pp. 282-289 [KL Blaxter, J Kielanowski and G Thorbek, editors]. Newcastle-upon-Tyne: Oriel Press.

van Milgen J, Bernier JF, Lecozler Y, Dubois S \& Noblet J (1998) Major determinants of fasting heat production and energetic cost of activity in growing pigs of different body weight and breed/castration combination. British Journal of Nutrition 79, $1-9$.

Webster AJ (1989) Energy utilization during growth and reproduction (discussion). In Energy Metabolism of Farm Animals, Proceedings of the Eleventh Symposium, Lunteren, The Netherlands, 18-24 September 1988, EAAP Publication no. 43, pp. 85-88 [Y van der Honing and WH Close, editors]. Wageningen: Pudoc.

Webster AJ, Lobley DE, Reeds PJ \& Pullar JD (1979) Protein mass, protein synthesis and heat loss in the Zucker rat. In Energy Metabolism, Proceedings of the Eighth Symposium on Energy Metabolism, Cambridge, September 1979, pp. 125-128 [L Mount, editor]. London: Butterworths.

Whittemore CT (1983) Development of recommended energy and protein allowances for growing pigs. Agricultural Systems 11, 159-186.

Whittemore CT (1997) An analysis of methods for the utilisation of net energy concepts to improve the accuracy of feed evaluation in diets for pigs. Animal Feed Science and Technology 68, 89-99.

Whittemore CT \& Fawcett RH (1976) Theoretical aspects of a flexible model to simulate protein and lipid growth in pigs. Animal Production 22, 87-96.

Yen J-T (1997) Oxygen consumption and energy flux of porcine splanchnic tissues. In Digestive Physiology in Pigs, Proceedings of the Seventh International Symposium on Digestive Physiology in Pigs, Saint Malo, France, 1997, EAAP Publication no. 88, pp. 260-269 [J-P Laplace, C Février and A Barbeau, editors] Paris: INRA.

Zoons J, Buyse J \& Decuypere E (1991) Mathematical models in broiler raising. World's Poultry Science Journal 47, 243-255. 